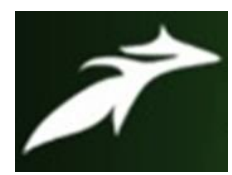

Shiva et al, International Journal of Advances in Agricultural Science and Technology,

Vol.8 Issue.9, September-2021, pg. 183-190

ISSN: 2348-1358

Impact Factor: 6.057

NAAS Rating: 3.77

\title{
Socio-Economic Characterization of Farmers Based on Content and Frequency of Messages Being Disseminated Through ICT Tools
}

\author{
Shiva $^{1^{*}}$; Syed H. Mazhar ${ }^{1}$; Dipak Kumar Bose ${ }^{1}$ \\ ${ }^{1}$ Department of Agricultural Extension and Communication, SHUATS, Prayagraj \\ *Corresponding email: singh2013.siva@ gmail.com
}

DOI: 10.47856/ijaast.2021.v08i9.020

\begin{abstract}
Socio-economic profile of farmers based on content and frequency of messages being disseminated through ICT tools was studied. ICT plays an important role among the farmers in the village of Pusa block as a source of keeping them updated and connected. The data has been collected from 120 farmers using ICT tools through face to face interview. Descriptive research design was followed for the study. The selection of block and villages was done purposively and randomly as per the ICT users. The study concludes that role of ICTs in agriculture development was influenced by content of information and the respondents age, caste, education, size of family, family type, social participation, family annual income, sources of information and size of land holding, high and medium level of knowledge about agricultural activities among farmers through ICT tools
\end{abstract}

Keywords: ICT, Farmers, e-Agriculture

\section{INTRODUCTION}

Agriculture in India is the core sector for food security, nutritional security and sustainable development and for poverty alleviation. It contributes approximately $16 \%$ of GDP. Milestone in agriculture development in India includes: Green Revolution, Blue Revolution and so on and the most recent one is Information and communication technology revolution. Information and Communication Technologies play an important role in disseminating information to farmers enabling them to decide on the cropping pattern, use of HYV seeds, fertilizer application, pest management and marketing. Information and Communication 


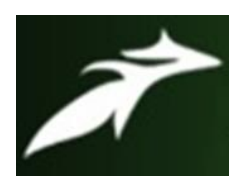

Shiva et al, International Journal of Advances in Agricultural Science and Technology, Vol.8 Issue.9, September-2021, pg. 183-190

ISSN: 2348-1358

Impact Factor: 6.057

NAAS Rating: 3.77

Technology is a stretched term for information technology (IT) which emphasis the role of unified communication and homogenization of telecommunication, computer as well as necessary software, its storage and the audio-visual systems, which permit all the users to access, store, transmit and manipulate information. The term ICT is also used to refer to the combination of audio-visual and telephone network with the computer networks through a single cabling or link system (aims.fao.org)

ICT is the study, design, development, application, implementation, support or the management of computer based information system. The term is commonly used as a synonym for computers and computer network, but it also circumscribes other information distribution technologies such as television and telephones ( $\operatorname{Rod} \boldsymbol{e t}$ al., 2012). ICT based on climate-smart agriculture can amplify agricultural productivity and sustainability mentioned in economic survey (2019). Information and communication technology help in dissemination or communication of information, transfer of technology, procurement of inputs and selling of output in way to help farmers by reducing their uses of material resources and manpower. Information and communication technology in agriculture also known as e-agriculture focuses on the enhancement of agricultural and rural development through improved information and communication process. Many ICT in agriculture or eagriculture interventions have been developed and tested around the world to help agriculturists improve their livelihoods through increased agricultural productivity and income or by reducing risk.

This study shows that most of the respondents were receiving information related to climate change and agriculture. They received information on information on inputs, production technology, credit information, marketing information, weather information, and other agricultural information, which they regarded as very helpful for their awareness and better farming practices. More than $50 \%$ of the farmers using different ICT tools stated that availed information through ICTs is very much informative and necessary for enabling their resilience and adaptation to climate change. 


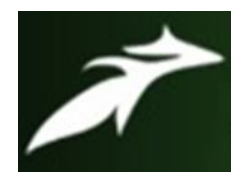

Shiva et al, International Journal of Advances in Agricultural Science and Technology, Vol.8 Issue.9, September-2021, pg. 183-190

ISSN: 2348-1358

Impact Factor: 6.057

NAAS Rating: 3.77

\section{RESEARCH METHOD}

The present study has been carried out during 2020-21 in Samastipur district of Bihar, the district lies situated between $25^{\circ} 30^{\prime} 00^{\prime \prime}$ to $26^{\circ} 05^{\prime} 00^{\prime \prime}$ latitudes north \& $85^{\circ} 37^{\prime} 50^{\prime \prime}$ to $86^{\circ} 23^{\prime} 30^{\prime \prime}$ longitude east. Agriculture is the main economic occupation of the district and about $83 \%$ of the total working population depends on it. Samastipur had a total population of 4.25 million of which 2,228,432 were males and 2,026,350 were females. The literacy rate of the district is 63.81\% (Census, 2011). Out of 20 blocks in Samastipur district, Pusa block has been selected by purposive sampling because awareness programmes is held by Rajendra Agriculture University regularly. In preparing the list, the help from resource personal and agricultural supervisor of the concerned area were taken for authenticity and counter check of the information. Out of 40 villages of Pusa block 8 villages has been selected for the study on the basis of no. of ICT users. Selection of farmers was done randomly from each village according to ICT users. The well structured interview schedule was developed for collection of data. The general of socio-economic attributes of the selected respondents i.e.., age, education, land holding, annual income, family size, family type, sources of information, participation in extension activities were consisted as a first part of schedule, and in the second part of schedule appropriate statistical tools were used for data interpretation.

\section{RESULT AND DISCUSSION}

\section{Distribution of socio-economic attributes of the selected respondent}

The socio-economic attributes of the selected respondent were given in table: 1. Majority of respondents were belonged to the age group of $35-55$ i.e. $37.50 \%$, while $25 \%$ farmers belonged to above 55 years age group and those belonged to age group of 55 above i.e. 26.67\%. The maximum ICT users (30\%) were graduated and above followed by intermediate (25\%), while $20.83 \%$ respondents had qualification upto high school, $16.66 \%$ respondents had qualification upto primary school, while $7.5 \%$ of respondents were illiterate respectively. When we talk about size of land holdings then it was found through survey that $69.1 \%$ of farmers had small size of land holdings followed by medium size of land holding (26.60\%), 


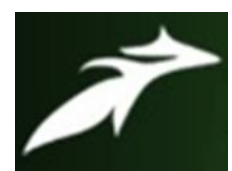

Shiva et al, International Journal of Advances in Agricultural Science and Technology,

Vol.8 Issue.9, September-2021, pg. 183-190

ISSN: 2348-1358

Impact Factor: 6.057

NAAS Rating: 3.77

and $4.16 \%$ of farmers having large size of land holding. The majority of respondents (53.33\%) had medium level of annual income i.e. 1,00,000 - 2,00,000. Followed by high level of annual income (29.16\%) i.e. 50,000-90,000, and (25.83\%) respondent had high level of annual income. Among all the respondents, majority of respondent (38.33\%) belonged to large size of family. While $38.33 \%$ respondent belonged to small size of family. The majority of respondents (53.33\%) had High level of knowledge about sources of information. And the majority of respondents were belonged to medium level of participation in extension activities.

Table: 1 Distribution of respondents according to their Socio- Economic Characteristics.

\begin{tabular}{|l|l|c|}
\hline S.No. & Category & Percentage \\
\hline $\mathbf{1 .}$ & Age & 37.5 \\
\hline & $25-35$ & 35.83 \\
\hline & $36-55$ & 26.67 \\
\hline & Above 55 & 32.50 \\
\hline 2. & Caste & 36.66 \\
\hline & UR & 30.83 \\
\hline & BC & \\
\hline & SC/ST & 74.17 \\
\hline 3. & Occupation & 25.83 \\
\hline & Farming & 7.5 \\
\hline & Employee cum Farming & 16.66 \\
\hline $\mathbf{4}$ & Education & 20.83 \\
\hline & Illiterate & 25 \\
\hline & Primary & 30 \\
\hline & High School & \\
\hline & Intermediate & 69.1 \\
\hline & Graduation and Above & 26.6 \\
\hline $\mathbf{5 .}$ & Size of land holding & 4.16 \\
\hline & Small Farmers up to 2 ha & 29.17 \\
\hline & Medium 2-4hac & 53.33 \\
\hline & Large Above 4 ha & 25.83 \\
\hline $\mathbf{6 .}$ & Annual income & \\
\hline & Low & \\
\hline & Medium & \\
\hline & High & \\
\hline & \multicolumn{2}{|l|}{} \\
\hline & \multicolumn{2}{|l|}{} \\
\hline
\end{tabular}




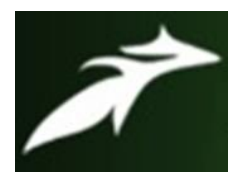

Shiva et al, International Journal of Advances in Agricultural Science and Technology,

Vol.8 Issue.9, September-2021, pg. 183-190

ISSN: 2348-1358

Impact Factor: 6.057

NAAS Rating: 3.77

\begin{tabular}{|l|l|c|}
\hline $\mathbf{7 .}$ & Family Size & 27.50 \\
\hline & Small size & 34.17 \\
\hline & Medium size & 38.33 \\
\hline & Large size & 46.67 \\
\hline $\mathbf{8 .}$ & Family types & 53.33 \\
\hline & Nuclear & \\
\hline & Joint & 14.17 \\
\hline $\mathbf{9 .}$ & Mass media exposure & 48.65 \\
\hline & Low & 37.18 \\
\hline & Medium & 23.33 \\
\hline & High & 46.66 \\
\hline $\mathbf{1 0 .}$ & Participation in extension activities & 30 \\
\hline & Low & \\
\hline & Medium & \multicolumn{2}{|l|}{} \\
\hline & High & \\
\hline & \multicolumn{2}{|l|}{} \\
\hline
\end{tabular}

\subsection{Content and frequency of messages}

10 different kind of information were found to be frequently disseminated through these four ICT tools being used by the respondents about improved agricultural technology were identified in this study. The frequency of information been used by the respondents for application of the information effectively. For this purpose, data regarding content and frequency of messages being disseminated through ICT tools were collected.

Table: 2 Distribution of respondents into different categories with respect to information gained from different ICT tools.

\begin{tabular}{|l|l|c|c|c|c|c|c|}
\hline \multirow{2}{*}{ S. No. } & \multirow{2}{*}{ Content } & \multicolumn{3}{|c|}{ Radio users (3) } & \multicolumn{3}{c|}{ Computer Users (10) } \\
\cline { 3 - 8 } & & Daily & Sometimes & Never & Daily & Sometimes & Never \\
\hline 1 & Info. On inputs & 0 & 2 & 1 & 0 & 2 & 8 \\
\hline 2 & Production Technology & 0 & 1 & 2 & 0 & 3 & 7 \\
\hline 3 & Credit Info. & 0 & 1 & 2 & 0 & 0 & 10 \\
\hline 4 & Marketing Info. & 0 & 0 & 0 & 0 & 1 & 9 \\
\hline 5 & Weather Info & 0 & 2 & 1 & 0 & 0 & 10 \\
\hline
\end{tabular}




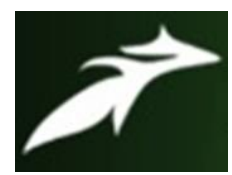

Shiva et al, International Journal of Advances in Agricultural Science and Technology,

Vol.8 Issue.9, September-2021, pg. 183-190

ISSN: 2348-1358

Impact Factor: 6.057

NAAS Rating: 3.77

\begin{tabular}{|l|l|l|l|l|l|l|c|}
\hline 6 & Crop Insurance Info. & 0 & 3 & 0 & 0 & 2 & 8 \\
\hline 7 & Govt. Schemes & 0 & 3 & 0 & 0 & 0 & 10 \\
\hline 8 & PHT Info. & 0 & 0 & 3 & 0 & 0 & 10 \\
\hline 9 & INM & 0 & 3 & 0 & 0 & 1 & 9 \\
\hline 10 & IPM & 0 & 2 & 1 & 0 & 0 & 10 \\
\hline
\end{tabular}

Table: 3 Distribution of respondents into different categories with respect information gained from different ICT tools

\begin{tabular}{|l|l|c|c|c|c|c|c|}
\hline \multirow{2}{*}{ S. No. } & \multirow{2}{*}{ Content } & \multicolumn{3}{|c|}{ Mobile Users (34) } & \multicolumn{3}{c|}{ TV \& Mobile Users(73) } \\
\cline { 3 - 8 } & & Daily & Sometimes & Never & Daily & Sometimes & Never \\
\hline 1 & Info. On inputs & $\mathbf{8}$ & $\mathbf{1 5}$ & $\mathbf{1 1}$ & $\mathbf{1 6}$ & $\mathbf{4 2}$ & $\mathbf{1 5}$ \\
\hline 2 & $\begin{array}{l}\text { Production } \\
\text { Technology }\end{array}$ & $\mathbf{1 8}$ & $\mathbf{1 2}$ & $\mathbf{4}$ & $\mathbf{9}$ & $\mathbf{1 8}$ & $\mathbf{4 6}$ \\
\hline 3 & Credit Info. & $\mathbf{1 2}$ & $\mathbf{1 2}$ & $\mathbf{1 0}$ & $\mathbf{1 8}$ & $\mathbf{1 4}$ & $\mathbf{4 1}$ \\
\hline 4 & Marketing Info. & $\mathbf{1 6}$ & $\mathbf{1 2}$ & $\mathbf{6}$ & $\mathbf{8}$ & $\mathbf{2 1}$ & $\mathbf{4 4}$ \\
\hline 5 & Weather Info & $\mathbf{2 0}$ & $\mathbf{1 0}$ & $\mathbf{4}$ & $\mathbf{4 2}$ & $\mathbf{1 7}$ & $\mathbf{1 4}$ \\
\hline 6 & Crop Insurance Info. & $\mathbf{0}$ & $\mathbf{2 0}$ & $\mathbf{1 4}$ & $\mathbf{0}$ & $\mathbf{6 3}$ & $\mathbf{1 0}$ \\
\hline 7 & Govt. Schemes & $\mathbf{5}$ & $\mathbf{1 6}$ & $\mathbf{1 3}$ & $\mathbf{0}$ & $\mathbf{3 2}$ & $\mathbf{4 1}$ \\
\hline 8 & PHT Info. & $\mathbf{0}$ & $\mathbf{5}$ & $\mathbf{2 9}$ & $\mathbf{0}$ & $\mathbf{1 3}$ & $\mathbf{6 0}$ \\
\hline 9 & INM & $\mathbf{1 3}$ & $\mathbf{8}$ & $\mathbf{1 3}$ & $\mathbf{0}$ & $\mathbf{1 4}$ & $\mathbf{5 9}$ \\
\hline 10 & IPM & $\mathbf{8}$ & $\mathbf{1 0}$ & $\mathbf{1 6}$ & $\mathbf{0}$ & $\mathbf{1 6}$ & $\mathbf{5 7}$ \\
\hline
\end{tabular}




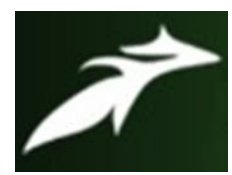

Shiva et al, International Journal of Advances in Agricultural Science and Technology,

Vol.8 Issue.9, September-2021, pg. 183-190

ISSN: 2348-1358

Impact Factor: 6.057

NAAS Rating: 3.77

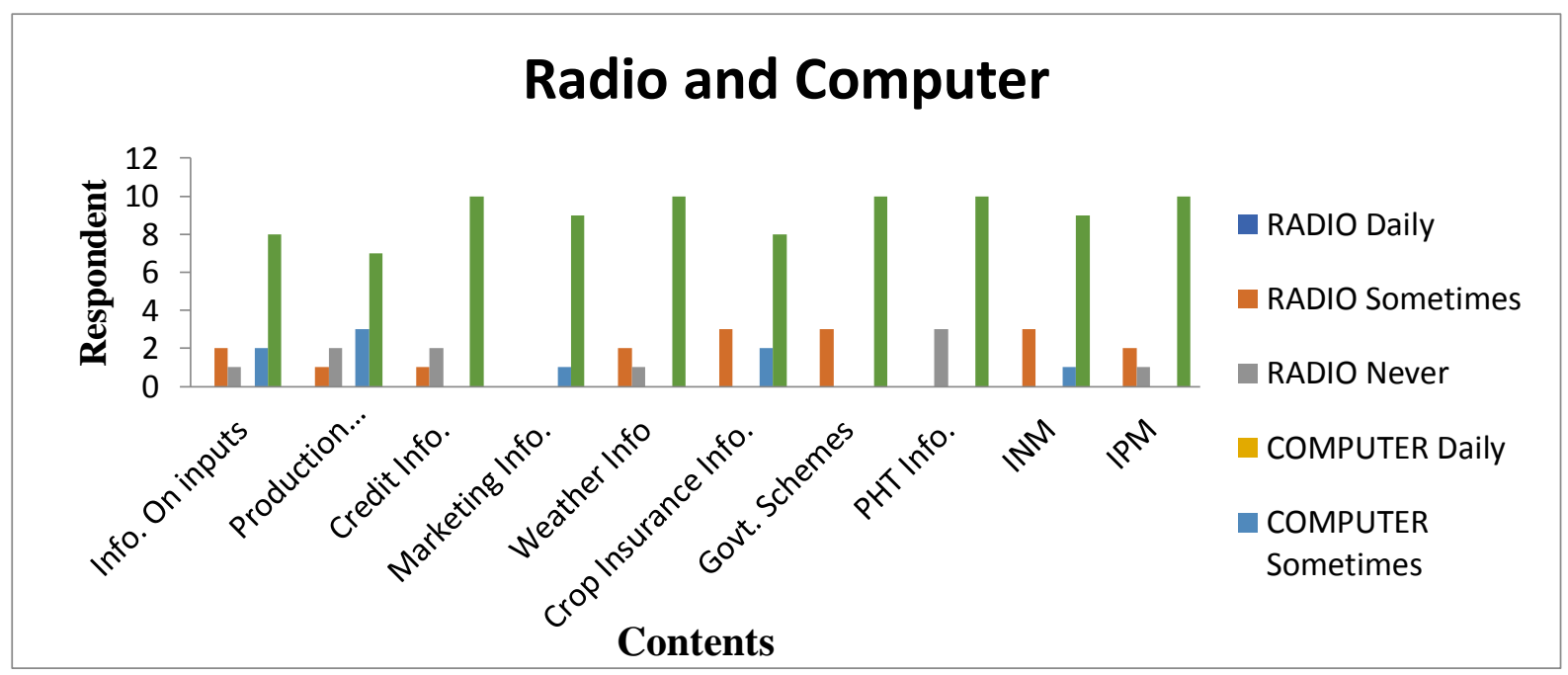

Fig: 1 Frequency of Information gained from Radio and Computer

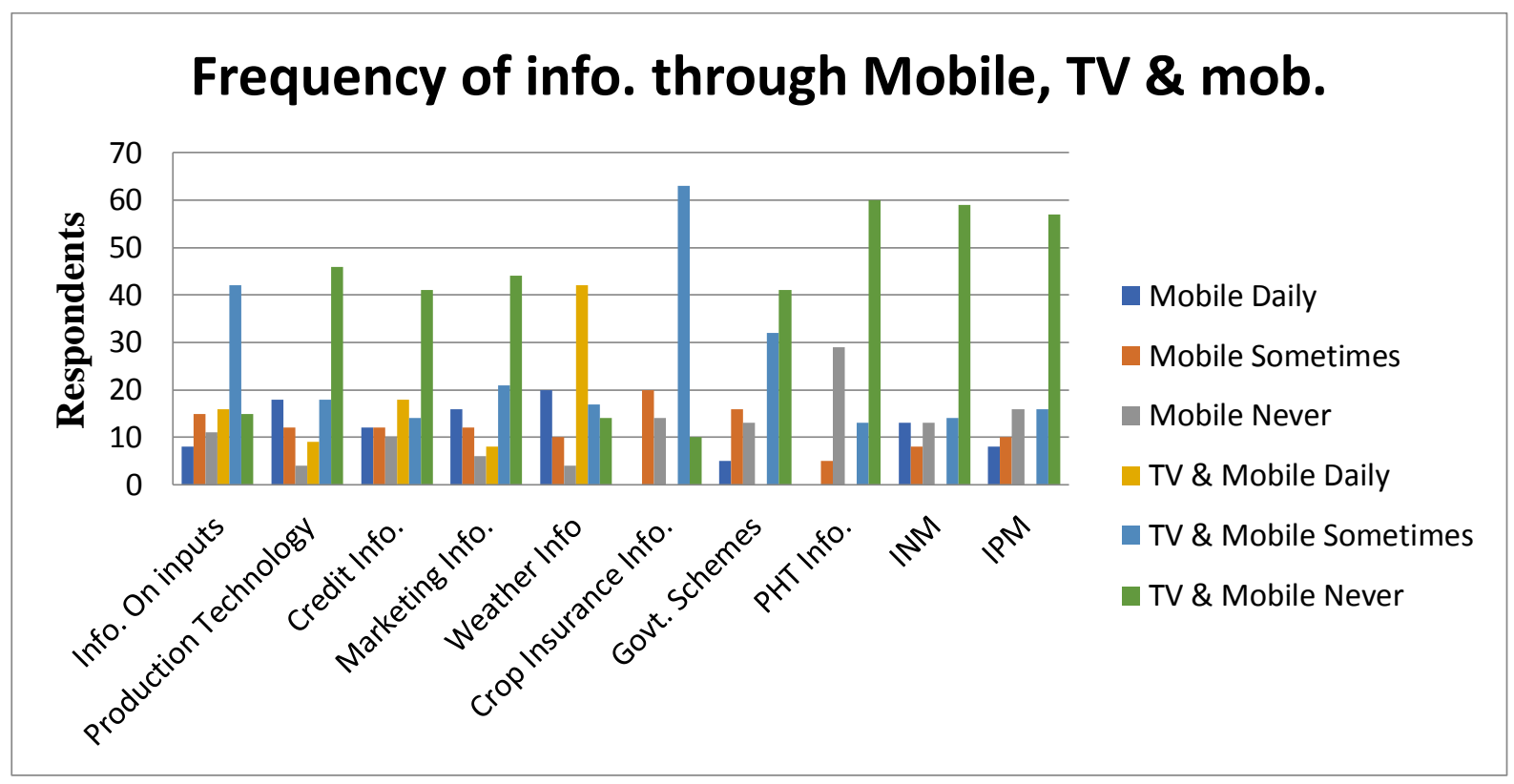

Fig: 2 Frequency of Information gained from TV and Mobile 


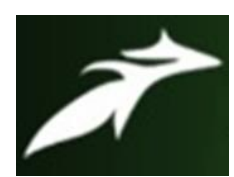

Shiva et al, International Journal of Advances in Agricultural Science and Technology, Vol.8 Issue.9, September-2021, pg. 183-190

ISSN: 2348-1358

Impact Factor: 6.057

NAAS Rating: 3.77

\section{Conclusion}

Based on the findings of the study, it was concluded that majority of the respondents were young age group had medium size of land holding. Majority of respondents were qualified more than high school level. Maximum number of respondents had medium level of income. Majority of respondents possess high level of source of information and majority of respondents had optimum level of utilization of ICT tools in adoption of improved agricultural practices. Reason behind the optimum level of the utilization of ICT tools were because the majority of the ICT users were from young age group and the people were frequently using the ICT tools viz Radio, Computer, Mobile, TV. Therefore, ICT tools with help farmers moving towards e-Agriculture.

\section{References}

[1]. Anonymous, 1991, Human Development Report. Oxford University Press. New York.

[2]. Banerjee A., 2011, The ICT in Agriculture: Bridging Bharat with India. Students' Research Global Media Journal - Indian Edition, 2(2), 1-16.

[3]. Devkota, N. and Phuyal, R.K., 2017, An Analysis of Nepalese Youth Understanding Level on Climate Change, Asian Journal of Economic Modelling, 5, 342-353. https://doi.org/10.18488/journal.8.2017.53.342.353

[4]. Indian council of food and agriculture 2017, ICT in Agriculture, National round table conference https://www.icfa.org.in/assets/doc/reports/ICT_in_Agriculture.pdf

[5]. NSSO, 2005, Situation Assessment Survey of Farmers - Access to Modern Technology for Farming, 59th Round (January - December 2003), National Sample Survey Organization (NSS), Ministry of Statistics and Programme Implementation, Government of India, New Delhi.

[6]. Singh S, Ahlawat S, Sanwal S., Role of ICT in Agriculture: Policy Implications, Orient.J. Comp. Sci. and Technol,10(3)

[7]. Tamubula, B.I. , Sseguya, H. , Miiro, R.,\& Okry F., 2019, Participation or legitimization? Assessment of quality of participation in farmer learning video production in central Uganda, The Journal of Agricultural Education and Extension, 26(3), 1-16.

[8]. UNDP, 2012, Promoting ICT based agricultural knowledge management to increase production and productivity of small holder farmers in Ethiopia. 